\title{
México como potencia mediana: una perspectiva histórica
}

Jürgen Bucbenau

UNIVERSIDAD OF SOUTHERN MISSISSIPPI

\begin{abstract}
Se analiza el papel de México como potencia mediana en el Caribe y Centroamérica, mismo que ha consistido en rechazar la intervención de Estados Unidos en la zona y en dar muestras de su riqueza relativa, en comparación con sus vecinos más pequeños. Enfrentar la influencia estadunidense ha sido tan sólo una de las preocupaciones del gobierno mexicano; tanto o más importantes han sido los asuntos bilaterales y la política doméstica para definir su posición como potencia mediana.
\end{abstract}

$\mathbf{L}$ os estudios más recientes han hecho referencia a México como una "potencia mediana", en comparación con Estados Unidos, el Caribe y Centroamérica: un Estado "más débil que las grandes potencias [...] pero significativamente más fuerte que otros países más débiles del sistema estatal vecino". ${ }^{1}$ Es de notar que los investigadores han analizado las iniciativas de México como las de una potencia mediana centroamericana, siendo que incluyen la injerencia en los conflictos frecuentes entre las

${ }^{1}$ Holbraad, Middle, 1984, p. 4. repúblicas del istmo, el apoyo al régimen sandinista en Nicaragua y, más recientemente, la negociación de pactos comerciales bilaterales para vincular Centroamérica al North American Free Trade Agreement (NAFTA) (Tratado de Libre Comercio) ${ }^{2}$ En otras investigaciones se analiza la política exterior mexicana hacia Cuba, sobre todo en los años sesenta, cuando los dirigentes mexicanos simpatizaban con los esfuerzos de Fidel Castro por permanecer en el poder, a pesar de la

${ }^{2}$ Por ejemplo, véase Mares, "Mexico", 1988, pp. 81-107; y Best, "Mexican", 1988. 
hostilidad de Estados Unidos. ${ }^{3}$ Otros investigadores estudian la posición independiente y nacionalista que suele adoptar México en organizaciones y conferencias internacionales tercermundistas, como la referida al "tercermundismo" de los años setenta. ${ }^{4}$

Estos estudios, y en especial los de carácter histórico, comparten una premisa importante: que las potencias medianas, como México, tratan de afirmar su influencia sobre estados pequeños, como Guatemala, debido a la prevención de éstos acerca de una gran potencia, como Estados Unidos. Muchos estudiosos sostienen que la influencia de este país no es sólo la limitación más importante que enfrenta el gobierno mexicano para establecer su política exterior, sino también la inspiración principal de su labor diplomática. Esta caracterización ubica a la política exterior mexicana en el marco de su relación con Estados Unidos, un país cuyos dirigentes consideran, desde hace mucho, a todo el mundo caribeño circundante, su "patio trasero". Las políticas mexicanas hacia los países latinoamericanos suelen ser, en consecuencia, intentos de desafiar la influencia de Estados Unidos en América Latina, reflejando casi siempre una actitud cautelosa y prudente, que obedece al poder de Estados Unidos para imponer una limitante externa. ${ }^{5}$

No obstante, este paradigma dominante, aunque "estructuralmente

\footnotetext{
${ }^{3}$ Pellicer, México, 1972.

${ }^{4}$ Consúltese, por ejemplo, Ojeda, Alcances, 1976.

sBuchenau, Sbadow, 1996.
}

realista", trivializa las variaciones temporales y espaciales de la formulación de la política exterior mexicana e ignora también la importancia de la política doméstica y de la ideología. ${ }^{6}$ Mediante un esbozo histórico de las políticas hacia Centroamérica y el Caribe, este trabajo argumenta que México constituye un ejemplo particularmente rico de potencia mediana: no sólo ha desafiado a la gran potencia local con sus acciones, sino que ha perseguido asimismo una gama amplia de objetivos. También afirma que, aunque muchas de estas metas están relacionadas con la influencia de Estados Unidos, su sola existencia revela que las relaciones con este país han sido construidas equivocadamente por tomar a dicho país como la única determinante de las políticas externas mexicanas y, por extensión, de las de muchos de los países latinoamericanos.

Los primeros intentos de México de afirmarse como una potencia mediana fueron infructuosos debido a la debilidad interna del país. Después de lograr la independencia en 1821, México, desgarrado por la inestabilidad política, se convirtió en víctima de la rivalidad de las grandes potencias. Entre 1821 y 1867, España, Francia, Inglaterra y Estados Unidos intervinieron en México, en parte para incrementar sus propios intereses, pero también para disminuir la influencia de sus rivales. El intento español de

\footnotetext{
${ }^{6}$ Para una definición del realismo estructural, véase Waltz, Theory, 1979. Para la actuación de las potencias medianas en un sistema internacional unifocal, véase Holbraad, Middle, 1984, pp. 93-98.
} 
reconquista, la guerra de los Pasteles, el conflicto respecto a Texas y la intervención francesa, debilitaron más la autoridad política nacional y, por tanto, hicieron imposible cualquier pretensión de adoptar una postura internacional de respaldo. En aquel momento, México no podía desempeñar un gran papel ni en el Caribe ni en Centroamérica. Ocasionalmente el gobierno mexicano trató de romper con su aislamiento tratando de congraciarse con alguna de las grandes potencias para presionar a otra, o para fomentar la solidaridad latinoamericana contra la intervención de la gran potencia. En 1827 apoyó la convocatoria de Simón Bolívar a la formación de una liga latinoamericana. El gobierno mexicano también trató de estrechar sus relaciones con Colombia, otra víctima frecuente de la intervención extranjera. ${ }^{7}$ En los años 1860 , el presidente Benito Juárez, estimulado por el gobierno de Estados Unidos, incitó la causa de la independencia de Cuba respecto a España. ${ }^{8}$ Pero estos esfuerzos esporádicos no tuvieron efectos duraderos: la política exterior mexicana del siglo XIX respondió, sobre todo, a las amenazas de anexión y de invasión.

Precisamente, debido a esta preocupación por las múltiples amenazas a su integridad territorial, Guatemala acabó siendo una excepción al modelo de inactividad mexicana seguido en América Latina. Como el resto de Centroamérica, Guatemala había formado parte del efímero imperio me-

\footnotetext{
${ }^{7}$ Roldán, Relaciones, 1974.

${ }^{8}$ Hamnett, Juárez, 1994, pp. 52-53.
}

xicano de Agustín de Iturbide, surgido como heredero del virreinato de Nueva España. Con la desintegración del imperio en 1823, Centroamérica se había separado de México, salvo la provincia de Chiapas que siguió unida a él. Ésta y toda su frontera oriental se convirtieron en objeto de una disputa larga y áspera: primero entre México y la Centroamérica unida y, más tarde, entre México y Guatemala, después de la desintegración de las Provincias Unidas de Centroamérica. En esta pelea con un vecino mucho más débil y pequeño, México llevó la voz cantante. ${ }^{9}$ Como es de suponer, su éxito en la frontera sudoriental contrastaba fuertemente con el mayor fracaso en su frontera norte, donde había perdido la mitad de su territorio, mismo que pasó a ser parte de Estados Unidos.

El gobierno estadunidense se mostró incapaz de interferir y nada dispuesto a ello, y el conflicto de Chiapas se emponzoñó y provocó finalmente la intervención de Guatemala en México. Durante la larga lucha de Juárez contra los insurgentes conservadores y las tropas de intervención francesas (1858-1867), el gobierno conservador guatemalteco apoyó a los separatistas chiapanecos y a una serie de dirigentes conservadores. ${ }^{10} \mathrm{En}$ este esfuerzo, las afinidades ideológicas entre los conservadores no contaban para nada, sino que tal intervención tenía por objeto arrebatar a Chiapas de las garras del "coloso del norte" que, para Gua-

${ }^{9}$ Benjamin, Rich, 1989, pp. 7-10; y Zorrilla, Relaciones, 1984.

${ }^{10}$ Dougherty, "México", 1969. 


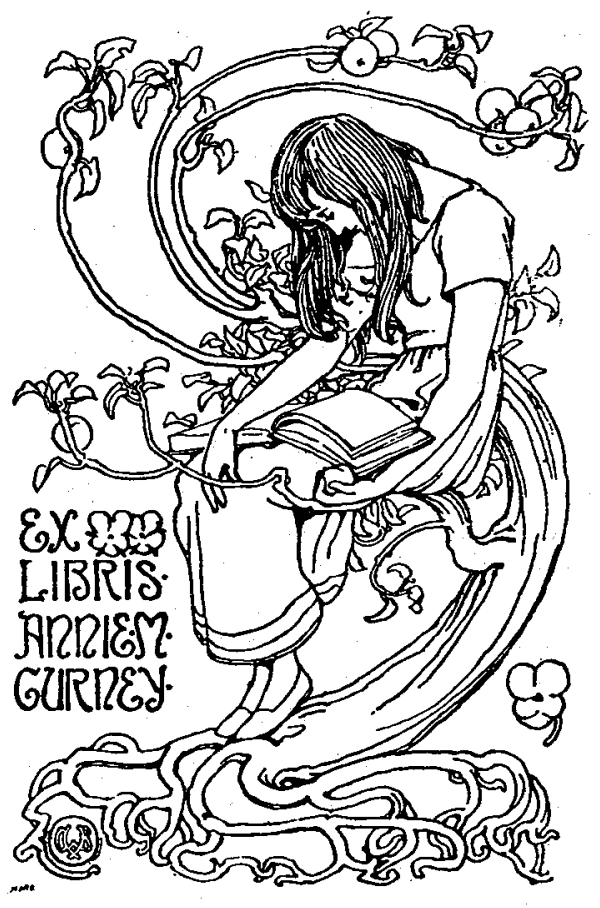

temala, no era México sino Estados Unidos. Chiapas era el Texas de Guatemala, y es por ello que el gobierno mexicano necesitaba tener el ojo puesto sobre el pequeño vecino del sureste.

No es de extrañar, por tanto, que Juárez ayudara con la caída de los conservadores guatemaltecos. En 1871 permitió que una banda de rebeldes liberales utilizara Chiapas como campo de entrenamiento, proporcionándoles además armas y municiones. Debido en parte a la ayuda de Juárez, los liberales consiguieron derrocar al gobierno conservador. ${ }^{11}$ Pero para de-

\footnotetext{
${ }^{11}$ Woodward, Rafael, 1993, p. 347; Clegern, Origins, 1993, p. 150.
}

cepción de muchos dirigentes mexicanos, los nuevos líderes guatemaltecos se mostraron al principio igualmente intransigentes respecto a la cuestión de Chiapas. No fue sino hasta 1882 cuando el problema se resolvió definitivamente, y fue porque el crecimiento de la lucrativa economía del café en la región de la frontera mexicano-guatemalteca, dependía de la solución del conflicto. Independientemente del resultado, las preocupaciones bilaterales y, tal vez, la simpatía por la causa liberal, habían llevado a la intervención de Juárez.

Mas la preocupación por la influencia de Estados Unidos en Centroamérica se hizo evidente apenas a principios de los años 1880 , cuando su secretario de Estado, James Blaine, preocupado sobre todo por la seguridad de las rutas comerciales entre el istmo de Tehuantepec y Panamá, presionó a México y a Guatemala para que llegaran a una solución. ${ }^{12}$ Pero el Tratado de 1882 sobre la frontera mexicano-guatemalteca no revelaría muchas huellas de esta presión, y aunque Blaine había apoyado la posición de Guatemala en la controversia, el Tratado, firmado después de que él dejó su cargo, significaría una ganancia territorial para México. ${ }^{13}$

Un análisis de la política exterior mexicana en el periodo 1821-1882 revela dos puntos importantes: el gobierno mexicano no siempre ha podido o ha querido afirmar una posición de potencia mediana, y no siempre ha actuado por miedo a la expansión

\footnotetext{
${ }^{12}$ Schoonover, "Intereses", 1996, pp. 13-14.

${ }^{13}$ Cosío Villegas, Historia, 1960 , vol. v, t. 2.
} 
de alguna gran potencia. Sólo una de sus iniciativas, el intento de crear una liga latinoamericana, fue lanzada con la intención de limitar la creciente influencia de Estados Unidos en América Latina; las políticas de la otra gran potencia regional, Gran Bretaña, nunca impulsaron a México a actuar. A medida que las anexiones estadunidense y las intervenciones curopeas fueron cosa del pasado, las propias ambiciones de México y sus continuos problemas con Guatemala se tornaron en la principal inspiración de las actividades mexicanas en el resto de América Latina.

A fines del siglo XIX, el control central efectivo alcanzado por el presidente Porfirio Díaz, permitió al gobierno mexicano desarrollar una política exterior activa en el mundo del Caribe. $\mathrm{Al}$ inagurar un periodo de crecimiento exportador, el régimen porfiriano no sólo anuló las revueltas sociales y a los caudillos regionales, sino que utilizó el poder estatal recién instaurado en el país para hacer de éste un actor en los asuntos internacionales. En 1883, los porfiristas renovaron el aparato diplomático para fortalecer la representación del país en el extranjero. Los focos primordiales de ubicación de la burocracia encargada de la política exterior de México fueron los países en vías de industrialización del Atlántico Norte, como originarios del capital de inversión necesario para la modernización y la estructuración del Estado. Pero la nueva diplomacia de Díaz también servía a un propósito adicional: una fuerte presencia mexicana en América Latina podía contribuir al establecimiento de su lide-
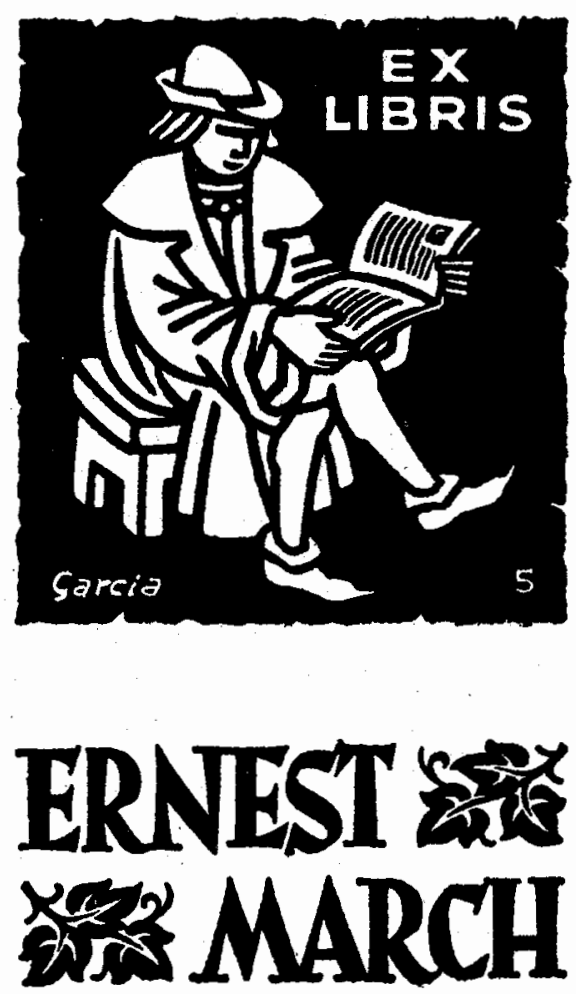

razgo al otorgar su régimen credenciales nacionalistas. ${ }^{14}$. El ascenso de Estados Unidos como líder en el Caribe y el papel que, en consecuencia, restó a las potencias europeas, hacían que esa posición fuera aún más importante.

Sin embargo, Díaz tuvo una vez más que prestar atención destacada a las relaciones bilaterales con Guate-

${ }^{14}$ Para este argumento, ver Deger, "Porfirian", 1979, esp. cap. 2, y Buchenau, Sbadow, 1996, pp. 22-108. 
mala. En marzo de 1885 , el presidente guatemalteco, Justo Rufino Barrios, amenazó con invadir El Salvador con la esperanza de convertirse en el jefe de un Estado centroamericano unificado. Imediatamente, el régimen de Díaz mostró a Barrios su desacuerdo con esta manifestación de fuerza. Así, el secretario de Relaciones Exteriores, Ignacio Mariscal, envió una nota de protesta a la ciudad de Guatemala y reiteró al gobierno salvadoreño su solidaridad. Para desviar una parte de las fuerzas invasoras de Barrios al oeste, Díaz envió tropas a la frontera guatemalteca. Después de haber estallado la guerra entre Guatemala y El Salvador, el embajador mexicano instó al gobierno de Estados Unidos a que se uniera a Díaz oponiéndose a las pretensiones de Barrios. Por tanto, cuando Barrios murió en batalla en El Salvador, México había contribuido en alguna medida a su derrota. ${ }^{15}$

Los motivos de Díaz para intervenir exigen, una vez más, la especificación del paradigma dominante. No cabe duda de que los dirigentes mexicanos temían que el dominio de Estados Unidos en el itsmo pudiera resultar beneficioso al ser ejercido con mano dura, y dado que una Centroamérica unificada ofrecería mejores condiciones para la construcción de un canal transísmico. Pero como la diplomacia de Estados Unidos había oscilado entre apoyar este tipo de unión y defender el statu quo con cinco entidades políticas pequeñas y más

${ }^{15}$ Cosío Villegas, Historia, 1960 , vol. v, t. 2 , pp. 404-465; Buchenau, Sbadow, 1996, pp. 3439. fácilmente manejables, esos temores no fueron los que orientaron la política de Díaz. Cualquier duda respecto a la posición de Estados Unidos desapareció al negarse Washington a reconocer a Barrios como jefe de un nuevo Estado centroamericano. No obstante, Díaz ayudó a El Salvador contra Guatemala por no permitir que se fortaleciera un país que, en su opinión, algún día podía amenazar a Chiapas. Por tanto, sus políticas en Centroamérica reflejaban, principalmente, sus preocupaciones sobre las ambiciones guatemaltecas, y sólo en lugar secundario, la capacidad de Estados Unidos de impulsar esas ambiciones. La presencia de la gran potencia en Centroamérica había influenciado la estrategia y los métodos no violentos de Díaz, pero no sus objetivos políticos. ${ }^{16}$

Con lo anterior no se quiere indicar, sin embargo, que el régimen porfiriano no reaccionara ante el crecimiento del poder estadunidense a finales de 1800. La posición de México en conferencias internacionales muestra que Díaz abogaba por un planteamiento latinoamericano colectivo para hacer frente a su influencia. En la conferencia interamericana de 1889 celebrada en Washington, D. C., México y Argentina encabezaron a un grupo de delegaciones latinoamericanas opuesto a la propuesta estadunidense de unir las aduanas continentales, misma que hubiera dado a las empresas estadunidenses una gran ventaja sobre sus competidores europeos. En reuniones subsiguientes, los delegados de Díaz contribuyeron a

${ }^{16}$ Buchenau, Shadow, 1996, pp. 22-48. 
suprimir varias iniciativas estadunidenses enfocadas a imponer el arbitraje obligatorio de los conflictos internacionales, lo cual hubiera permitido la injerencia de Estados Unidos en los litigios entre México y Guatemala. Ocasionalmente, Díaz también asestó algún golpe a los proyectos hegemónicos de Estados Unidos. En 1896 se unió a Argentina para oponerse a los intentos del secretario de Estado, Richard Olney, para que se considerara a la doctrina Monroe un dictamen de derecho internacional. Estados Unidos no tenía derecho, declaró Díaz, a aplicar esta doctrina unilateralmente, y convocó a que se elaborara un pacto de solidaridad colectiva, a través del cual todos los Estados americanos se comprometían a ayudar a cualquiera de los Estados signatarios en caso de ataque. ${ }^{17}$

A finales del siglo XIX, la influencia de Estados Unidos constriñó cada vez más las políticas de México como potencia mediana, aunque no llegó a determinarlas. El régimen de Díaz no se preocupó por antagonizar con el gobierno de Estados Unidos en asuntos sin importancia para México, pero sí en los que eran mayormente importantes para Estados Unidos. En cuanto a estas cuestiones, que el Departamento de Estado consideraba vitales, el gobierno de Díaz sólo podía resguardar sus intereses con la mayor cautela. Esto fue obvio en las posturas que adoptó México respecto a la guerra cubano-hispano-americana y a la cuestión del canal de Panamá.

\footnotetext{
${ }^{17}$ Porfirio Díaz, mensaje al H. Congreso, 1 de abril de 1896 en González, Presidentes, 1966, pp. 462-463.
}

Díaz tenía muchas razones para apoyar la lucha por la independencia cubana. Muchos mexicanos, sobre todo en las ciudades, habían seguido esa guerra civil, con décadas de duración, entre los insurgentes cubanos y la administración colonial española. Teniendo en mente la propia experiencia de México en cuanto a la intervención europea, y entusiasta de las ideas de algunos rebeldes cubanos, como José Martí, gran parte del público letrado aplaudió la ayuda de México a la rebelión. Además, el destino político de Cuba afectaba a la seguridad de México, ya que Cuba ocupaba las dos entradas más importantes al Golfo de México. Desde la perspectiva mexicana, no era deseable que continuara la presencia española en Cuba. ${ }^{18}$

Sin embargo, los peligros inherentes a este involucramiento excedían a las ventajas. Al igual que el régimen de Díaz, el gobierno estadunidense de Grover Cleveland apoyaba la independencia de Cuba, pero por diferentes razones. Es cierto que Cleveland y asociados compartían la oposición general de Díaz al colonialismo europeo. Pero las similitudes terminaban ahí. Tanto por razones estratégicas como por motivos económicos, el gobierno de Estados Unidos quería extender su propia (aunque informal) influencia en Cuba en lugar de la española. Mas la posibilidad de un crecimiento del poderío estadunidense a costa del español en la isla, era aún menos deseable para Díaz, aunque este crecimiento era inevitable si Estados Unidos y España iban a la gue-

${ }^{18}$ Deger, "Porfirian", 1979, pp. 235-238. 
rra. ${ }^{19}$ Por tanto, Díaz no tenía más opción que el intento de mediar entre los insurgentes cubanos, el gobierno español y los dirigentes estadunidenses, con la esperanza de impedirla. No obstante, cuando la retórica antiespañola de la prensa amarillista de William R. Hearst llegó a un nivel febril a fines de 1897, Díaz comprendió que cualquier intento de mediación era equivalente a jugar con fuego. En consecuencia, no atendió a los ruegos de muchos de sus asociados para que actuara, y dejó pasar la oportunidad de figurar como un héroe nacionalista. Cuando las armadas de Estados Unidos y España entraron en colisión, con el resultado del fin del imperio colonial español y el comienzo de un pequeño imperio americano, tanto el gobierno mexicano como la prensa que éste subsidiaba, permanecieron cobardemente callados. Para dar alguna salida a la tensión, Díaz dio un cierto margen a los periódicos de oposición para que protestaran por las políticas estadunidenses, pero él nunca hizo ningún comentario sobre el asunto. ${ }^{20}$

Asimismo, el gobierno mexicano no trató de interferir en las dificultades de Estados Unidos para obtener de Colombia la tan deseada concesión del canal de Panamá. El proyectado canal podía rendir muchos beneficios a México, por ello Díaz apoyó la construcción de una vía de agua finan-

${ }^{19}$ La mejor evaluación de la política estadunidense en torno a Cuba se encuentra en Pérez, Cuba, 1990.

${ }^{20}$ Ibid., pp. 235-275; Riguzzi, "México", 1992, p. 414 . ciada por Estados Unidos, pero no podía aprobar, sino con reservas, las acciones de Estados Unidos al descarriarse las negociaciones. Cuando el Senado de Colombia se resistió a la ratificación del Tratado del canal, porque otorgaba concesiones políticas y territoriales extraordinarias a Estados Unidos, el presidente Theodore Roosevelt alentó y ayudó a los separatistas panameños para que establecieran la nueva República de Panamá. Una vez más, Díaz no pudo oponerse a las acciones estadunidenses, y muchos de sus defensores nacionalistas lo abandonaron; no obstante que las medidas tomadas por Estados Unidos constituían, como mínimo, una violación de las prácticas internacionales de reconocimiento diplomático, cuando no una intervención descarada, el gobierno mexicano se negó a hacer comentarios sobre el asunto. Como única señal de la oposición mexicana a dichas medidas, Díaz se negó a otorgar un reconocimiento inmediato al nuevo gobierno panameño. ${ }^{21}$

Esta gran cautela respecto a Estados Unidos, que ganó a los porfiristas la enemistad de los fervientes nacionalistas mexicanos, pone de relieve las importantes variaciones regionales ejercidas en las políticas latinoamericanas del país. México se comportó muy agresivamente con su vecino inmediato, Guatemala, y apoyó al resto de Centroamérica contra las pretensiones guatemaltecas, pero se movió con el más profundo comedimiento

${ }^{21}$ Zorrilla, Historia, 1965 , t. 2, p. 190; Mariscal a Manuel Azpiroz, México, 4 de enero de 1904, AHSRE, exp. 15-11-24. 
en el Caribe. A pesar de la retórica, los gobiernos mexicanos más recientes han seguido este mismo patrón. ${ }^{22}$

Con la construcción de un canal transoceánico controlado por Estados Unidos, la conducta de México como potencia mediana cambió una vez más. Con el fin de proteger el canal y las inversiones de sus ciudadanos, él Departamento de Estado estadunidense trató de acabar con las luchas periódicas entre los países centroamericanos. En consecuencia, la prevención de la intervención militar de Estados Unidos en el istmo no tardó en convertirse en la meta principal de Díaz, y los porfiristas volvieron así a fijarse en Centroamérica.

Por fortuna, Theodore Roosevelt deseaba evitar el ejercicio de una función policiaca unilateral en la zona. Este presidente elogió con frecuencia a México como uno de los líderes del hemisferio, y hasta llegó a sugerir al embajador de Díaz que México se anexara los países centroamericanos. ${ }^{23}$ Díaz se negó a convertirse en la mampara de Roosevelt en Centroamérica, pero comprendió que la cooperación con Estados Unidos podría permitirle detener su intervención militar y los propósitos agresivos del presidente guatemalteco, Manuel Estrada Cabrera. Por tanto, aceptó hacer de mediador, junto con Estados Unidos, en los conflictos centroamericanos.

\footnotetext{
${ }^{22}$ No fue casualidad que el presidente Carlos Salinas de Gortari se callara cuando, en 1994, parecía inminente una invasión a Haití encabezada por la OEA.

${ }^{23}$ Azpiroz a SRE, Washington, 24 de diciembre de 1904, AHSRE, exp. L-E-1845, pp. 315-317.
}

Entre mayo de 1906 y marzo de 1909, esta mediación conjunta produjo resultados muy provechosos. Ambos países contribuyeron a poner fin a la guerra entre Guatemala y El Salvador, mediaron entre Honduras y Nicaragua, y hasta tomaron parte en la negociación de los tratados de Washington de 1907. Aunque estos tratados se deterioraron más tarde por las ambiciones de una serie de hombres fuertes centroamericanos, fue el tratado de paz más amplio, hasta la fecha, entre los países centroamericanos, y fue un logro significativo que no sólo aplazó la intervención estadunidense, sino que sirvió con posterioridad como marco de referencia para los mecanismos de arbitraje de la liga de las Naciones y de la OEA. Esta mediación compartida resultó beneficiosa para ambos países: su participación ayudó a Estados Unidos en sus esfuerzos diplomáticos y dio al gobierno de Díaz una oportunidad de influir en la política de Estados Unidos. Mientras Roosevelt ocupó la presidencia, esta estrategia fue fructífera. En las negociaciones, él trató a Díaz en condiciones de paridad, y no fue más allá de situar buques de guerra a una cierta distancia de la costa centroamericana cuando la paz estuvo amenazada. ${ }^{24}$

Pero el sucesor de Roosevelt, William H. Taft, destruyó este acuerdo y adoptó una postura más seca. Cuando su gobierno trató de obtener la ayuda de México para derrocar al régimen de José Santos Zelaya en Nicaragua -hombre duro y de sentimientos antiestadunidenses, dado que el Congre-

${ }^{24}$ Buchenau, Shadow, 1996, pp. 73-78. 
so de Estados Unidos había elegido la ruta de Panamá para el canal, en vez de la de Nicaragua-, Díaz puso fin a su cooperación; y al renunciar Zelaya, tras una revuelta apoyada por Estados Unidos en diciembre de 1909 , los porfiristas le dieron asilo. También apoyaron a su sucesor, designado a dedo para detener la rebelión, arriesgando incluso, con ello, un deterioro de las relaciones México-Estados Unidos. Pero, en definitiva, Díaz no pudo impedir el triunfo de la facción declarada a favor de Estados Unidos. ${ }^{25}$

La hipótesis predominante explica importantes aspectos de la política exterior mexicana durante el periodo de 1903-1911: que mediante la cooperación o la confrontación, Díaz había detenido la intervención de Estados Unidos en Centroamérica. En cambio, la antigua meta de poner freno a las ambiciones guatemaltecas había perdido importancia, aunque seguía siendo significativa.

Una lectura atenta de los documentos revela también componentes políticos e ideológicos nacionales, asimismo importantes para la política exterior de fines del porfiriato: Díaz y sus asesores consideraban a Centroamérica inferior. En opinión de un diplomático prominente, México tenía el deber de vigilar la región con "mirada paternal" para que los centroamericanos pudieran aprender de su experiencia dolorosa pero fructífera. ${ }^{26}$ Los porfiristas se congratulaban

${ }^{25}$ Buchenau, "Counter-intervention", 1993 , pp. 227-252.

${ }^{26}$ Gamboa a SRE, Managua, 19 de febrero de 1900, AHSRE, exp. 6-13-107. de poder mostrar al público mexicano la prosperidad, la estabilidad y el progreso relativos de su país. El papel de México como socio oficial de Estados Unidos, lo presentaba como incorporado a las filas de los países "avanzados" pero, en realidad, la política exterior de Díaz, aunque reconocía sus límites para desafiar a Estados Unidos, mostraba a los mexicanos la larga trayectoria que el país había recorrido en el curso del porfiriato. La posición de potencia mediana que Díaz había dado a México acentuó los sentimientos nacionalistas de las clases alta y media mexicanas $y$, al menos en parte, ésta se había concebido con los objetivos nacionales en mente. El hecho de que la dictadura porfiriana, cada vez más brutal, titubeara en definitiva (debido en parte a las expectativas nacionalistas que había despertado), no afecta a la observación de que su política exterior sí estaba a tono con la opinión nacional. ${ }^{27}$

El estallido de la revolución mexicana en 1910 dejó a México sin capacidad de continuar ocupándose de objetivos prioritarios en Centroamérica y el Caribe. Como en el periodo de 1821-1867, la política exterior fue víctima de la inestabilidad política y de la intervención extranjera. En consecuencia, una vez más México se convirtió virtualmente en un "poder inexistente" durante el periodo de 19101920. Al contrario de lo que muchos estudiosos han afirmado, el gobierno revolucionario de Venustiano Carranza nunca trató de "exportar" principios de "nacionalismo revolucionario"

${ }^{27}$ González, "Dictatorship", 1992, p. 176. 
en ningún sentido ${ }^{28}$ Aparte de mucha retórica panhispánica y una diatriba contra la doctrina Monroe, Carranza nunca pudo plantearse el oponerse a la influencia de Estados Unidos en América Latina. ${ }^{29}$

Al igual que en el siglo XIX, los conflictos de México con Guatemala reaparecieron. El dictador guatemalteco, Manuel Estrada Cabrera, trató de aprovecharse de la inquietud reinante en México. Sin detenerse a considerar el escenario político transitorio de la ciudad de México, Estrada (como los gobiernos guatemaltecos de décadas atrás) apoyó a los separatistas chiapanecos y a la contrarrevolución dirigida por Félix Díaz. Y lo mismo que Juárez, Venustiano Carranza, dirigente de la facción constitucionalista eventualmente triunfante, trató de desquitarse dando refugio a los disidentes guatemaltecos. Al final, ninguno de estos esfuerzos de desestabilización tuvo éxito; pero el episodio mostró que los periodos de guerra civil y revolución habían centrado la atención de México, como era de prever, en las cuestiones bilaterales y territoriales con sus dos vecinos. ${ }^{30}$

Fue al presidente Plutarco Elías Calles (1924-1928) a quien correspon-

${ }^{28}$ Richmond, Venustiano, 1983, pp. 211 217; Ewing, "Carranza's", 1952; McMullen, “Calles", 1980, p. 5.

${ }^{29}$ Presidentes, 1988 , t. 1, p. 440; Richmond, Venustiano, 1983, p. 211.

${ }^{30}$ Leavell a secretary of State, Guatemala, 21 de marzo de 1916, NAw, DF 814.00/262; Avrel a ministro de Asuntos Exteriores, Guatemala, 11 de octubre de 1915, AMAE, Nouvelle Sperie, Guatemala, vol. 2: Politique Intérieure, 138; Lehmann a Bethmann-Hollweg, Guatemala, 3 de octubre de 1915, AAB, serie IA, R 16896. dió después reafirmar la posición de México como potencia mediana. En el Caribe no había entonces ocasión para ello, pero él no tardó en encontrar una brecha en Centroamérica: estrechó relaciones con Guatemala y lanzó una serie de planes destinados a fomentar la comprensión y la simpatía entre México y los países centroamericanos, que incluían programas de radio e intercambios de estudiantes. ${ }^{31}$

Mas la oportunidad mejor se presentó en Nicaragua. Desde junio de 1926 Calles había apoyado la causa de la facción liberal en rebelión contra el gobierno usurpador de un conservador partidario de Estados Unidos, el general Emiliano Chamorro. Calles había actuado en un momento que parecía propicio pues, con la intención de desembarazarse de sus ya viejos compromisos militares en América Latina, el gobierno de Estados Unidos había retirado sus tropas de Nicaragua; además, su secretario de Estado, Frank B. Kellogg, parecía simpatizar con la posición de México, puesto que se negaba a reconocer a Chamorro como jefe de Estado legítimo de ese país. Asimismo, el dirigente liberal Juan Bautista Sacasa, como vicepresidente, podía reivindicar la representación del orden constitucional. Pero, al final, el despliegue de marines estadunidense obligó a Calles a retirarse: Kellogg percibió la injerencia mexicana en Nicaragua çomo una amenaza a la posición de Estados Unidos en el istmo y trató de que Nicaragua adoptara una postura agresiva, con el fin de forzar al gobierno mexicano a ren-

${ }^{31}$ Beals, "Mexico", 1926, pp. 836-840. 
dirse a las reclamaciones estadunidenses por los daños y perjuicios ocasionados por la revolución y por la nueva Constitución nacionalista mexicana. ${ }^{32}$ Por todo lo anterior, fue mucho más difícil para Calles que para Díaz hacer jugar a México el papel de potencia mediana, ya que él no gozaba de las relaciones relativamente cordiales de los porfiristas con la gran potencia.

¿Por qué México ya no podía desempeñar un papel de potencia mediana sin arriesgarse a la enemistad del gobierno de Estados Unidos? La Constitución ya mencionada, en la que se declaraba patrimonio de la nación el subsuelo rico en petróleo, era parte del problema. La legislación nacionalista, los reclamos estadunidenses por los mencionados daños y perjuicios, las políticas anticlericales y un gobierno estadunidense intransigente, era una combinación idónea para agriar las relaciones Estados UnidosMéxico.

Otro elemento de similar importancia fue el cambio del contexto internacional. Antes de la primera guerra mundial, Estados Unidos aún tenía motivos para temer a la diplomacia europea de las cañoneras, y de ahí la buena disposición de Roosevelt para permitir que México participara en el mantenimiento de la paz en Centroamérica. Pero con la guerra, la posición económica y política de Estados Unidos en Latinoamérica había mejorado mucho. En 1920 su gobierno ni necesitaba ni quería que México fuera una potencia mediana en la zona. A la vez, las prioridades del

\footnotetext{
${ }^{32}$ Salisbury, Imperialism, 1989, cap. 5.
}

gobierno mexicano también habían cambiado. Los regímenes revolucionarios, enfrentados a la abrumadora tarea de la reconstrucción nacional, ni siquiera se podían plantear la reafirmación de la postura de Díaz, aunque no carecían de apoyo popular para ejercer activismo internacional. ${ }^{33}$

¿Fue la intervención mexicana en Nicaragua un intento de desafiar a Estados Unidos, como lo indicaría nuestro paradigma principal? Aunque los diplomáticos estadunidenses de la epoca así lo creían (influyendo en la opinión de los historiadores que se basaban, sobre todo, en los archivos de Estados Unidos), el registro histórico indica otra cosa. La intervención nicaragüense complicó las ya tormentosas relaciones Estados Unidos-México, y el retiro definitivo de Calles no le aportó honores en su propio país. Es aún más significativo que las pruebas mexicanas de archivo indiquen que el régimen de Calles no contempló su empresa nicaragüense como un reto a la influencia de Estados Unidos, aunque México prometió ayuda a Sacasa a fin de expandir su propia influencia en Centroamérica. El hecho de que la influencia estadunidense hubiera disminuido con la dimisión de Chamorro, es una consideración secundaria. ${ }^{34}$

Después del embrollo nicaragüense, México ya no actuó como una potencia mediana. La política internacional militó contra el activismo me-

\footnotetext{
${ }^{33}$ Véase, por ejemplo, la decision del presidente Lázaro Cárdenas de ayudar a la facción republicana en la guerra civil española. Powell, México, 1980.

${ }^{34}$ Ver AHSRE, exp. 20-2-15.
} 
xicano: los conflictos sucesivos de Estados Unidos con el Eje y la Unión Soviética tornaron peligrosas las políticas exteriores mexicanas de carácter independiente en el periodo 19381970. Esto se hizo obvio en la política de México, antes y después del golpe de Estado patrocinado por la CIA, que derribó a un gobierno reformista en Guatemala en marzo de 1954. Cuando el gobierno de Estados Unidos presentó para su aprobación una resolución contra el comunismo internacional a la Décima Conferencia Interamericana celebrada en Caracas (resolución que parecía una cobertura para una futura intervención en Guatemala), la delegación mexicana se abstuvo de tomar posición al respecto. Pero una vez derrocado allí el gobierno de Arbenz, no hubo ni una sola palabra de protesta de fuentes oficiales en la ciudad de México. Aunque estaba profundamente descontento respecto a la intervención de Estados Unidos, el gobierno mexicano no osó manifestarse en contra en el pleno clima anticomunista de la guerra fría. ${ }^{35}$ Pero sí hubo un caso en que México tomó un rumbo independiente. Frente a los persistentes esfuerzos de Estados Unidos por evitarlo, mantuvo relaciones diplomáticas formales con la Cuba de Fidel Castro, paso que le ganó el apoyo popular al régimen de Adolfo López Mateos. ${ }^{36}$

La relativa inactividad de México después de la segunda guerra mundial no fue sólo producto de su posición internacional, como lo indicaría

${ }^{35}$ Best, "Mexican", 1983, pp. 172-184.

${ }^{36}$ Pellicer, México, 1972. el paradigma predominante. La política interna no favorecía su activismo internacional en aquella época: después de la presidencia de Lázaro Cárdenas (1934-1940), la llamada "revolución institucional" dio un fuerte viraje a la derecha. Muchos de los presidentes de México de la época -Ávila Camacho, Miguel Alemán Valdés, Adolfo Ruiz Cortines o Gustavo Díaz Ordaz- no compartieron el interés personal de Díaz o de Calles en el resto de América Latina. Por tanto, después de la nacionalización de la industria petrolera del país en 1938, el blanco de la política mexicana viró hacia dentro: en la época del "milagro mexicano", de 1946 a 1968, el interés del gobierno por el resto de América Latina se mantuvo sólo, a "nivel sentimental" ${ }^{37}$ Una política exterior activista no sólo podía perjudicar la próspera relación empresarial de México con Estados Unidos, sino que, además, los políticos del país se mostraban muy precavidos ante el riesgo de agitar la controversia en el país entrando en estrechas relaciones con las dictaduras represoras de derecha en Centroamérica o con la Cuba de Castro.

México resurgió como una potencia mediana a principios de los años setenta, en plena crisis nacional debido a la masacre de Tlatelolco de 1968. Sin embargo, el presidente Luis Echeverría, que como secretario de Gobernación había ordenado la matanza, se proclamó paladín de la lucha del tercer mundo por un nuevo orden mundial más justo. Él actuó, sobre todo, a través de las agencias internacionales:

${ }^{37}$ Chabat, "Mexico", 1993, p. 56. 
su gobierno patrocinó la Carta de Derechos y Deberes Económicos de los Estados, aprobada por la Asamblea General de la onU en 1974. Un año después, México presionó para que se hicieran enmiendas a la carta de la OEA que ayudaron a Cuba a restablecer vínculos comerciales y diplomátiços con los demás países latinoamericanos. Pero las metas más ambiciosas de Echeverría siguieron sin ser satisfechas. A pesar de sus grandes esfuerzos, no consiguió que aumentaran notablemente los vínculos económicos entre México y sus vecinos latinoamericanos. Hacia fines de la década, el porcentaje de la región en el total del comercio mexicano, aún rondaba el $5 \% .^{38} \mathrm{La}$ finalidad del activismo de Echeverría no era, por tanto, el predominio de Estados Unidos en América Latina: esto parece reafirmar, en consecuencia, la hipótesis de que la política latinoamericana de México busca, sobre todo, disminuir la influencia de Estados Unidos. ${ }^{39}$

Mas una mirada más atenta al retorno de México a su nivel de potencia mediana despierta incertidumbre respecto a esta afirmación. No cabe duda de que México tenía más espacio para actuar en los años setenta, cuando el Watergate y la guerra de Vietnam captaban la atención estadunidense. Se podría decir, por tanto, que lo hecho por Echeverría fue aprovechar este nuevo espacio para actuar. Pero el estrecho vínculo cronológico entre la crisis de legitimidad del gobierno mexicano y sus protes-

${ }^{38}$ Ibid.

${ }^{39}$ Green, "México", 1977, pp. 1-4. tas de tercermundismo indican que sus iniciativas también podrían haber respondido a otro motivo: sobornar a la desencantada izquierda mexicana para apaciguarla. ${ }^{40}$

El ejemplo más espectacular del nuevo activismo internacional de México ocurrió durante el sexenio del sucesor de Echeverría, José López Portillo: el apoyo a la revolución sandinista en Nicaragua. México fue el primer país en romper relaciones con el dictador nicaragüense Luis Somoza Debayle; la Junta sandinista llegó a Managua en un avión mexicano y, después del triunfo de la revolución en julio de 1979, el régimen de López Portillo apareció como uno de sus principales benefactores internacionales. Luego, México ayudó también a los sandinistas de otras maneras: muchas veces trató de mediar entre la Nicaragua revolucionaria y el gobierno hostil de Ronald Reagan. ${ }^{41}$

En 1981, López Portillo dio un paso más: a la vez que el presidente francés François Mitterrand, declaró que los rebeldes marxistas del FMLN en El Salvador -un movimiento más radical que los sandinistas- merecían el grado internacional de "fuerzas políticas representativas del pueblo salvadoreño". ${ }^{\not 2}$ Esta declaración contribuyó a que los rebeldes salvadoreños cobra-

${ }^{40}$ Grabendorff, "Mexico", 1978, pp. 85-90.

${ }^{41}$ Véase Ojeda, Relaciones, 1985; Bagley, "Mexico", 1984, pp. 261-284; Grabendorff, "Role", 1984, pp. 83-100; Herrera y Ojeda, "Política", 1983, pp. 423-440; Pellicer, "Mexico", 1983,pp. 119-133; y Ojeda, "Mexican", 1983, pp. 135-160.

\{2 Jauberth, Castañeda y Hernández, Difficult, 1992, p. 33. 
ran un gran prestigio, y los alentó en su lucha contra los militares represores de El Salvador; fue además una bofetada para el gobierno de Reagan.

Pero en 1982, México tuvo una vez más que retirarse de esta posición independiente de apoyo a la izquierda. ${ }^{43} \mathrm{Al}$ patrocinar a los contras, Reagan hizo obvio que no iba a tolerár que el movimiento socialista sandinista siguiera en el poder. Al mismo tiempo, el inicio de una grave crisis económica y fiscal, que complicó la crisis política ya existente, obligó al gobierno mexicano a centrarse en sus propios problemas. ${ }^{44} \mathrm{~A}$ partir de entonces, México limitó su política latinoamericana a su participación como mediador en el tratado de Contadora. Aunque no fue muy fructífero, este tratado permitió al gobierno mexicano conservar un papel activo en los conflictos centroamericanos, no obstante sus infortunios económicos.

La intención de obstruir la intervención de Estados Unidos en Nicaragua jugó un importante papel en la decisión de López Portillo de ayudar a los sandinistas. A principios de 1979, el gobierno de Estados Unidos buscaba imponer una alternativa a Somoza; pero éste era un somocismo sin Somoza, e impuesto, hubiera tenido por resultado convertir a Nicaragua en un protectorado de facto. Otra alternativa a ese protectorado era aún más difícil de calibrar: desde finales de los setenta, Cuba había apoyado a los revolucionarios sandinistas, y éstos ha458.

${ }^{43}$ Herrera y Chavarría, "México", 1984, p.

${ }^{41}$ Bagley, "Mexican", 1983, pp. 406-409. bían llegado al poder con Castro como su único aliado internacional; pero la intervención militar de Estados Unidos hubiera sido una confirmación del somocismo. De ahi que la rápida ruptura de las relaciones con Somoza, y la ayuda material y política de México a los revolucionarios, correspondieran a la necesidad del gobierno mexicano de detener esa intervención de Estados Unidos en Nicaragua. ${ }^{45}$ La participación del país en ${ }_{*}$ el tratado de Contadora también apuntaría a impedir que Estados Unidos se involucrara militarmente en Centroamérica. Pero, una vez más, poner la influencia de Estados Unidos en el centro de las políticas realizadas por México en calidad de potencia mediana, no nos cuenta toda la historia. Mientras México desafiaba a Estados Unidos en Nicaragua, su política respecto a la guerra civil entre los militares represores y la izquierda insurgente en Guatemala era muy congruente con los objetivos estadunidenses. Temeroso de que un triunfo rebelde pudiera amenazar la estabilidad del país, el gobierno mexicano cooperó activamente con Estados Unidos y Guatemala para contener la insurrección. ${ }^{46}$

El comienzo del proyecto de liberalización económica del presidente Miguel de la Madrid y sus sucesores, Carlos Salinas de Gortari y Ernesto Zedillo, ha introducido una nueva fase en la condición de México como potencia mediana. Tanto por necesidad como por elección, México ha

\footnotetext{
${ }^{45}$ Ojeda, "Mexican", 1983, pp. 141-144.

${ }^{46}$ Aguilar, "Mexico", 1983, pp. 161-163.
} 


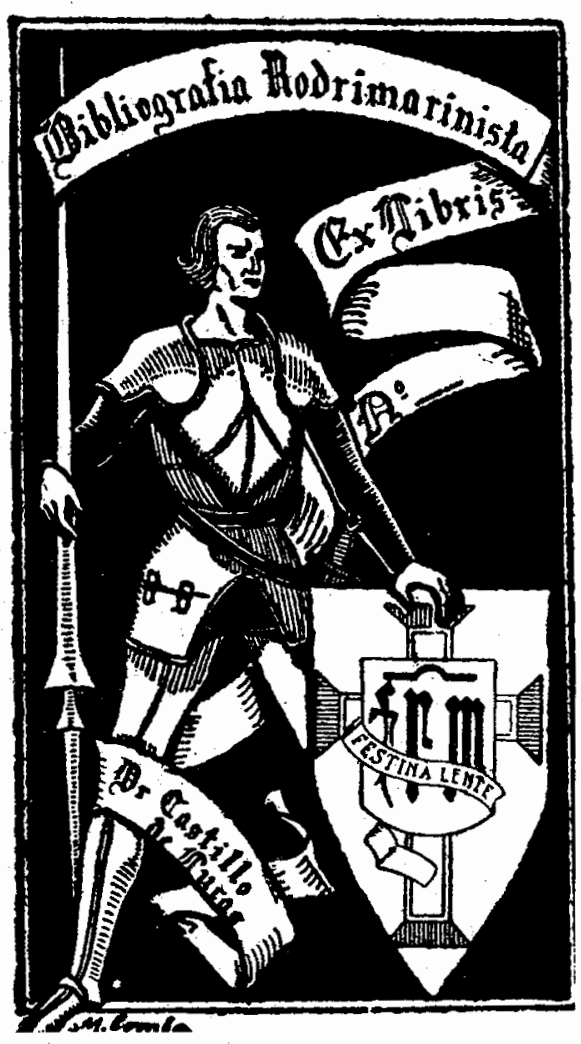

compartido su suerte con América del Norte más que nunca, y sus vínculos con el resto de América Latina han pasado a ser de importancia secundaria: con el TLC, parece poco probable un reto de México a Estados Unidos en Centroamérica o el Caribe; así que la tradicionalmente entendida posición de México como potencia mediana en América Latina ha llegado a su fin, al menos en el futuro inmediato.

Pero como lo ha demostrado este análisis, para México hay mucho más en juego que el reto a la influencia estadunidense. Comparado con su predecesor, Salinas de Gortari incrementó la presencia diplomática mexicana en América Latina. Y la negociación de un acuerdo de libre comercio con Chile y la firma de tratados bilaterales, que hacen de México un intermediario entre los países centroamericanos, así como el nuevo mercado unificado de Norteamérica señala el comienzo de su nueva dimensión como potencia "económica" mediana. México podría ser un apéndice pobre de Estados Unidos que sólo ocasionalmente prestara atención a sus hermanos centroamericanos y caribeños aún más pobres. Mas siempre que el gobierno mexicano ha desempeñado un papel activo en la región, lo ha hecho con un sinnúmero de motivos en mente.

México no es simplemente una "potencia mediana" en el sentido de estar atrapada entre Estados Unidos, mucho más fuerte, y la presencia estadunidense en los países centroamericanos y caribeños, mucho más débiles. El término "potencia mediana" se refiere a la gama de capacidades del país, tanto hacia la gran potencia, como hacia sus vecinos más débiles. Cuando el gobierno mexicano ha desempeñado estas capacidades, confrontar la influencia de Estados Unidos ha sido sólo una de sus preocupaciones, aunque de suma importancia. Del mismo modo, el poder relativo de Estados Unidos, en comparación con el de México, no ha sido nunca la única limitación a las políticas mexicanas. A lo largo de la historia de México como país independiente, las oportunidades y las limitaciones bilaterales y nacionales han sido 
igualmente importantes, si no es que más.

El análisis que se ofrece en este ensayo muestra una definición alternativa del concepto de potencia mediana. Las potencias medianas, como México, actúan en un sistema internacional caracterizado por dos realidades: 1) que la gran potencia o la hegemónica afecta fundamentalmente a la sociedad y a la política de la potencia mediana e igualmente de los pequeños Estados vecinos; 2) que la potencia mediana desempeña un papel limitado, pero esencial, en la sociedad y en la política de uno o de varios de los pequeños Estados.

El ejemplo de México muestra que las relaciones internacionales no son simplemente un tablero de ajedrez en el que torres y peones lidian por sus respectivas posiciones, siempre pendientes de las poderosas reinas que merodean por el territorio. La política exterior de las potencias medianas -lo mismo que la de las grandes potencias- responde a una serie de estímulos y limitaciones nacionales e internacionales relacionados entre sí. El estudio del comportamiento de las potencias medianas, dentro del contexto del sistema internacional produce algunos resultados interesantes, pero sólo cuando los investigadores presten, al menos, la misma atención a las dimensiones políticas, económicas e ideológicas internas de la política exterior (algo que la mayoría de los expertos en las relaciones exteriores de Estados Unidos han hecho por décadas), podremos entender la dinámica y el significado de la diplomacia de las potencias medianas.

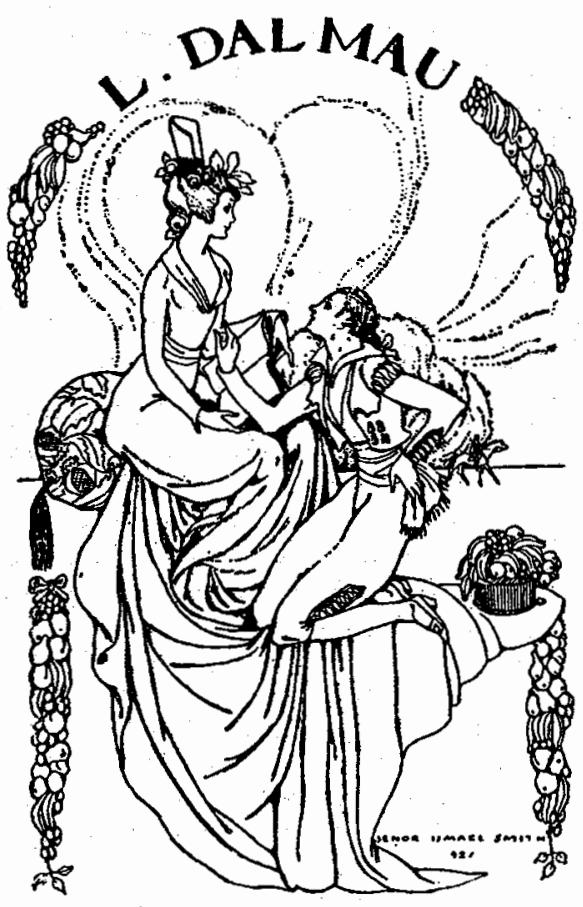

FUENTES CITADAS

\section{Fuentes primarias}

Archive du Ministere des Affaires Étrangeres, París, Francia (AMAE)

Archivo Histórico de la Secretaría de Relaciones Exteriores, México, D.F. (AHSRE).

González y González, Luis, Los presidentes de México ante la nación, Cámara de Diputados, México, 1966, 4 tomos.

Los presidentes de México: discursos políticos, 1910-1988, Presidencia de la República/El Colegio de México, México, 1988, 2 tomos. 
National Archives, Washington, D.C., Estados Unidos, Records of the Department of State, Record Group 59 (NAW).

Politisches Archiv, Auswärtiges Amt, Bonn, Alemania (AAB).

\section{Fuentes secundarias}

Aguilar Zínser, Adolfo, "Mexico and the guatemalan crisis" en Fagen, Future of Central America, s. e., 1983.

Bagley, Bruce M., "Mexican foreign policy: The decline of a regional power?", Current History, vol. 82, dic. 1983, pp. 406-409.

$\longrightarrow$ "Mexico in Central America: The limits of regional power" en Grabendorff, Political change in Central America, 1984.

Beals, Carleton, "Mexico seeking central american leadership", Current History, 24, sep. 1926, pp. 836-840.

Benjamin, Thomas, A rich land, a poor people: politics and society in modern Chiapas, University of New Mexico Press, Albuquerque, 1989.

Best, Edward H., "Mexican foreign policy and Central America since the mexican revolution", tesis doctoral, Oxford University, Oxford, 1988.

Buchenau, Jürgen, "Counter-intervention against uncle Sam: Mexico's support for nicaraguan nationalism", The Americas, vol. 50, t. 2, octubre 1993, pp. 227-252.

In the shadow of the giant:

The making of Mexico's Central America policy, 1876-1930, University of Alabama Press, 'Tuscaloosa, 1996.

Centro de Estudios Internacionales, Continuidad y cambio en la politica exterior de México: 1977, El Colegio de México, México, 1977.

Chabat, Jorge, "Mexico: so close to the United States, so far from Latin America", Current History, vol. 92, febrero 1993, pp. 56-60.
Clegern, Wayne M., The origins of liberal dictatorship in Central America: Guatemala, 1865-1873, University of Colorado Press, Boulder, 1993.

Cosío Villegas, Daniel (comp.), Historia moderna de México, Editorial Hermes, México, 1956-1973, 10 tomos.

Deger, Robert J., "Porfirian foreign policy and mexican nationalism: a study of cooperation and conflict in mexican-american relations, 1884-1904", tesis doctoral, Indiana University, Bloomington, 1979.

Dougherty, John E., "Mexico and Guatemala, 1856-1872: a case study in extralegal international relations", tesis doctoral, University of California, Los Ángeles, 1969.

Ewing, Floyd F., "Carranza's foreign relations: an experiment in nationalism", tesis doctoral, University of Texas, Austin, 1952.

Fagen, Richard R. y Olga Pellicer de Brody (comps.), The future of Central America: policy cboices for the United States and Mexico, Stanford University Press, Stanford, 1983.

González, Luis, "The dictatorship of Porfirio Diaz" en Hamill, Caudillos: dictators in Spanish America, 1992.

Grabendorff, Wolf, "Mexico's foreign policy: indeed a foreign policy?", Journal of Inter-American Studies and World Affairs, vol. 20, t. 1, 1978, pp. 85-90.

, "The role of regional powers in Central America: Mexico, Venezuela, Cuba and Colombia", en Muñoz, Latin American Nations, 1984, pp. 83100.

Heinrich-W. Krumwiede y Jörg Todt (comps.), Political change in Central America: internal and external dimensions, Westview Press, Boulder, 1984.

Green, Rosario, "México. La política exterior del nuevo régimen" en Continuidad y cambio, Centro de.Estudios Internacionales, 1977, pp. 1-4. 
Hamill, Hugh M. (comp.), Caudillos: dictators in spanish America, University of Oklahoma Press, Norman, 1992.

Hamnett, Brian, Juárez, Longman, Londres, 1994.

Herrera Zúñiga, René y Manuel Chavarría, "México en Contadora: una búsqueda de límites a su compromiso en Centroamérica", Foro Internacional, vol. 23, t. 4, abril 1983, pp. 423-440.

Herrera Zúñiga, René y Mario Ojeda, "La política de México en la región de Centroamérica", Foro Internacional, vol. 23 núm 4, abril 1993.

Holbraad, Carsten, Middle powers in international politics, St. Martin Press, Nueva York, 1984.

Jauberth, H. Rodrigo, Gilberto Castañeda, Jesús Hernández et al., The difficult triangle: Mexico, Central America and the United States, Westview Press, Boulder, 1992.

Mares, David, "Mexico's foreign policy as a middle power: The Nicaragua connection", Latin American Research Review, vol. 18, t. 3, 1988, pp. 81-107.

McMullen, Christopher J., "Calles and the diplomacy of revolution: mexicanamerican relations, 1924-1928", tesis doctoral, Georgetown University, Washington, 1980.

Ojeda, Mario (comp.), Las relaciones de México con los países de América Central, El Colegio de México, México, 1985.

$\longrightarrow$, Alcances y limites de la politica exterior mexicana, El Colegio de México, México, 1976.

-, "Mexican policy toward central America in the Context of U.S.-Mexico relations" en Fagen, Future of Central America, 1983.

Pellicer de Brody, Olga, México y la revolución cubana, El Colegio de México, México, 1972. rica: The difficult exercise of regional power" en Fagen, Future of Central America, 1983.

Pérez, Louis A, Cuba and the United States: ties of singular intimacy, University of Georgia Press, Athens, 1990.

Powell, Thomas G., Mexico and the spanish civil war, University of New Mexico Press, Albuquerque, 1980.

Richmond, Douglas, Venustiano Carranza's nationalist struggle, University of Nebraska Press, Lincoln, 1983.

Riguzzi, Paolo, "México, Estados Unidos y Gran Bretaña: una difícil relación triangular", Historia Mexicana, vol. 41, enero 1992, pp. 365-436.

Roldán Oquendo, Ornán, Las relaciones entre México y Colombia, 1810-1862, Secretaría de Relaciones Exteriores, México, 1974.

Salisbury, Richard V., Imperialism and intervention in Central America, Scholarly Resources, Wilmington, 1989.

Schoonover, Thomas D., "Los intereses europeos y estadunidenses en las relaciones políticas México-Guatemala", Secuencia, vol. 34, enero 1996, pp. 7-30.

Waltz, Kenneth, Theory of international politics, Random House, Nueva York, 1979.

Woodward, Ralph L., Rafael Carrera and the emergence of the Republic of Guatemala, 1821-1871, University of Georgia Press, Athens, 1993.

Zorrilla, Luis G., Historia de las relaciones entre México y los Estados Unidos de América, 1800-1958, Editorial Porrúa, México, 1965, 2 tomos.

la República de Centro America la República de Centro América y con Guatemala, Editorial Porrúa, México, 1984. 


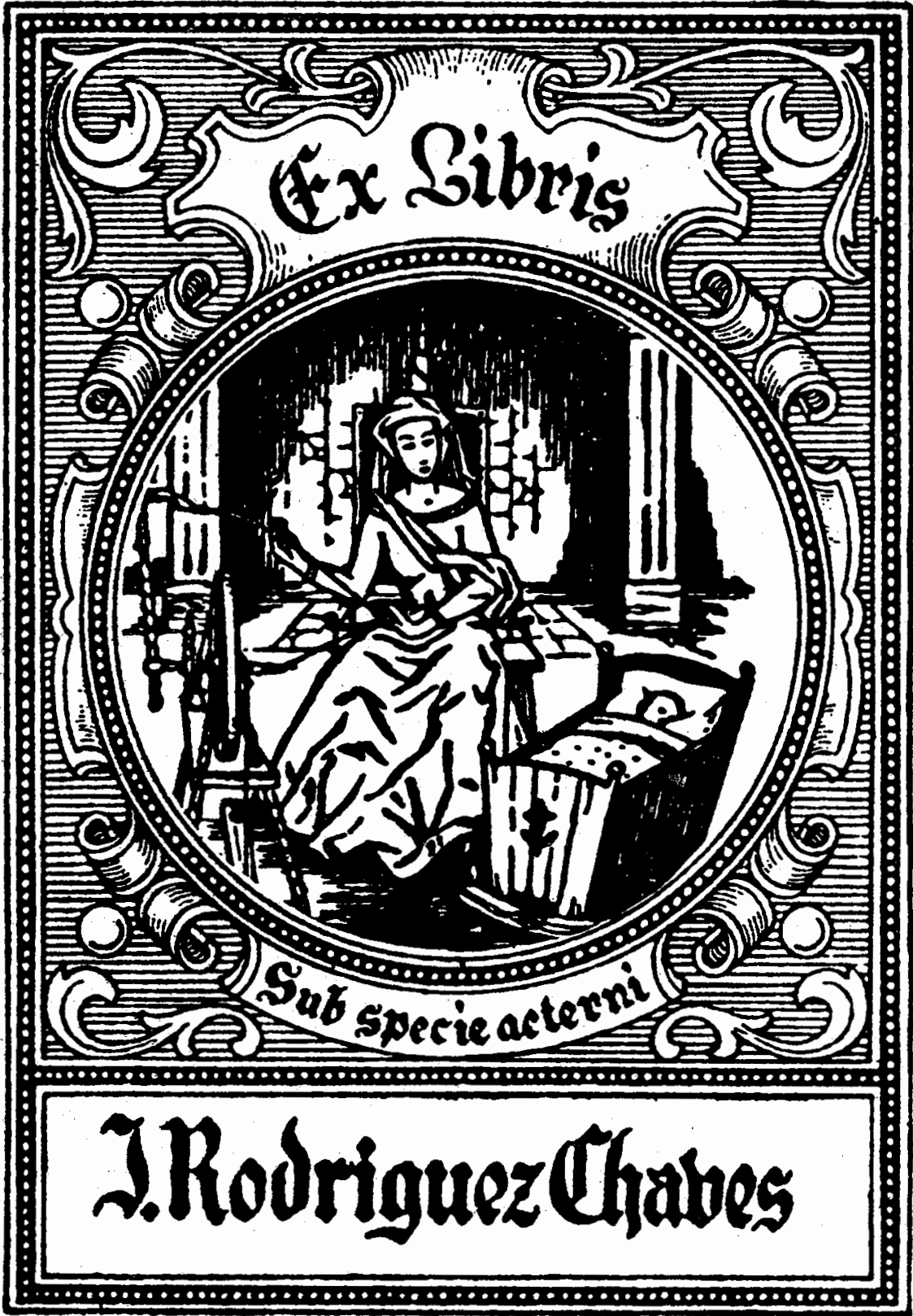

